\title{
THE PROVISION OF TOUGHNESS IN ONE AND TWO PHASE POLYMERS
}

\author{
R. N. HAWARD \\ Department of Chemistry, University of Birmingham, Birmingham 15, UK \\ and \\ C. B. BUCKNALL \\ Department of Materials, Cranfield Institute of Technology, Cranfield, Bedford, UK
}

\begin{abstract}
In a simple impact experiment with a Hookean solid, such as a glass beam, the energy absorbed is simply related to the modulus of elasticity and fracture strength at short times. However, with plastics under nearly all conditions, the energy absorption due to pure elastic deformations is small and toughness is achieved through large deformations taking place after yield. Even in "brittle" plastics the energy required for crack propagation is mainly determined by the plastic deformation processes, such as crazing, which take place in a small volume of material at the crack tip. In such cases a major factor in determining the total energy absorbed by the test-piece is the volume of plastically strained material.

Generally it is found that plastic deformation processes in polymers tend to be unstable leading to large localised strains instead of to uniform deformation. This is seen in necking under tension and in shear bands. A basic condition for such localization is the occurrence of strain softening and, in tension, material attenuation-as originally proposed by Considere. This conclusion is broadly in line with known stress-strain relations. For example, in the case of polycarbonate it can be shown that an annealing treatment leads to increased strain softening, a decrease in the volume of plastic strain during impact and a lower impact strength. This occurs without changes in relaxation behaviour.

Since the energy absorbed in the brittle fracture of many plastics involves crazing, which is of course a plastic deformation process with high energy absorption, the multiplication of crazes also increases the volume of plastically strained material and therefore the amount of energy which can be absorbed by the test-piece. This is conventionally achieved by adding suitably dispersed and adhesive particles of rubber to an otherwise brittle polymer such as polystyrene.

However, the introduction of an elastomer not only promotes crazing but, especially with the tougher types of matrix, it can initiate shear bands and even bulk yielding. These effects may be demonstrated in A.B.S. plastics by monitoring volumne changes and by a variety of other techniques. In this way the capability of the matrix to absorb energy during plastic deformation is spread through the test-piece so that products of very high impact strength can be made.
\end{abstract}

The toughness of plastics is most conveniently measured by means of a suitable impact test. Such tests measure the energy required to fracture the test piece under an applied blow. The results obtained are generally regarded as qualitative only, though essential for many purposes, but their precise significance is often questioned. However, considerable progress has now been made in the case of brittle fracture, where the conditions defined by Tattersall and Tappin ${ }^{1}$ apply. These may be defined in terms of the elastically recoverable energy stored in the test piece $(U)$ and of the energy $G_{c}$ required to propagate unit area of a crack (area $A$ ).

Here $-\mathrm{d} U / \mathrm{d} A=G_{c}$ is the original Griffith-Irwin condition for crack growth. ${ }^{2}$

Further, where $-\mathrm{d}^{2} U / \mathrm{d} A^{2}$ is always positive, the energy stored in the test-piece at the time of fracture initiation will be sufficient to break the sample completely.

Thus true brittle fracture is "initiation controlled" and the impact strength is simply the energy required to initiate fracture. These conditions are met in the case of impact on a simple beam or plate of a solid which obeys Hooke's Law. Ordinary glass provides a material with suitable properties. The theoretical treatment for the case of a "flexible" beam i.e. a beam which bends and breaks under the maximum tensile stress has been given by Preston and Glathart ${ }^{3}$ following the treatment which

†Here weight is used in an engineering sense i.e. $W=\mathrm{gM}$.
Preston originally ascribed to Tuckerman ${ }^{4}$ and the experiments of Haward. ${ }^{5}$ If a weight $W \dagger$ is dropped a height $h$ onto a beam of volume $V$ with a Young's Modulus E, then the maximum momentary tensile stress is

$$
\sigma=3 \sqrt{ }\left(\frac{2 W h \mathrm{E}}{V}\right)
$$

and if $\sigma_{f}^{t}$ is the breaking stress in time $t$ then:

$$
W h=\text { Energy to break }=\frac{1}{18} \frac{\left(\sigma_{f}^{t}\right)^{2} V}{\mathrm{E}}
$$

i.e. the energy to break is proportional to the volume of the beam. This formula has been tested by breaking glass beams under a static load and by means of a heavy pendulum. Fracture time and stresses were then calculated to provide the ratio $\left(\left(\sigma_{f}^{t}\right) \operatorname{impact} /\left(\sigma_{f}^{t}\right)\right.$ static) and these could be compared with (extrapolated) long-time experiments in which the relation between fracture stress and fracture time had been measured. The results obtained from a series of measurements ${ }^{5}$ on differently sized beams and plates are given in Table1.

Such results indicate that this type of impact experiment is reasonably quantitative. It follows immediately that the way to increase the impact strength of glass is to increase $\left(\sigma_{f}^{t}\right)$, and when this is achieved by means of the conventional toughening process similarly predictable in- 
Table 1. The fracture stress of glass beams and plates under impact and static loading

\begin{tabular}{|c|c|c|c|c|}
\hline \multirow{3}{*}{ Ratio } & \multirow[b]{2}{*}{$\left(\sigma_{f}^{t}\right)$ Impact } & \multirow{2}{*}{ Experimental } & \multicolumn{2}{|c|}{ Glass beams Glass plate } \\
\hline & & & 1.58 & 1.91 \\
\hline & $\left(\sigma_{f}^{t}\right)$ Static & $\begin{array}{l}\text { Predicted from } \\
\text { known time } \\
\text { effect }\end{array}$ & 1.73 & 2.04 \\
\hline
\end{tabular}

creases in impact strength (and decreases in the coefficient of variation) are obtained. ${ }^{6}$

With the glass specimens treated above, the effect of surface condition varying from one test-piece to another was eliminated by giving all results as an average of 20 or more individual experiments. However recent developments in fracture mechanics ${ }^{7,8,9}$ now make it possible to correlate impact measurements with sharp notched specimens over a whole range of sizes and crack lengths. In this way both Brown ${ }^{8}$ and Plati and Williams 9 successfully correlated the impact strength of razor cut specimens of various polymers, including polymethyl methacrylate, polycarbonate and polyethylene terephthalate, using equations derived from fracture mechanics, and obtained a value of $G_{c}$ for each material under impact conditions (Fig. 1). Homogeneous polymer samples of this type, which have a low ratio of (notch tip radius/sample width) will generally break in a brittle-crazing mode under plane strain conditions, meeting at the same time the conditions for brittle fracture summarised by Tattersall and Tappin. ${ }^{1}$

Now it is a requirement of the brittle fracture process, as interpreted according to the theories of Griffith ${ }^{2}$ and Berry ${ }^{10}$ that the stored elastic energy should be conveyed quantitatively to the propagating point of the crack. Therefore if this energy is in part dissipated in the polymer then the crack growth process will be impeded, and impact strengths measured under apparently brittle fracture conditions will increase in the same sense as the loss factor $(\tan \delta)$.

This effect has been demonstrated by Vincent, who also induced brittle fracture under impact in a number of

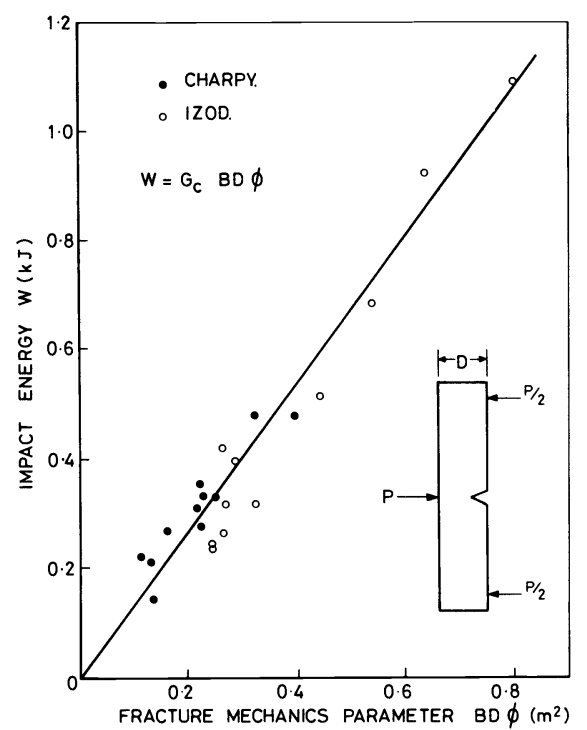

Fig. 1. Initiation-controlled impact fracture of poly(methyl methacrylate). Razor-notched specimens of thickness $B$, notch depth $a$ and compliance $C$. Dimensionless factor $\phi=$ $C \mathrm{~d}(a / D) / \mathrm{d} C$. Slope $G_{c}=1.3 \mathrm{~kJ} / \mathrm{m}^{2}$. After Plati and Williams. ${ }^{9}$ different polymers by using sharp notches and obtained results which corresponded directly to relaxation peaks. ${ }^{11}$ An example taken from his work is given in Fig. 2.

Under conditions of brittle fracture the energy to break is absorbed by small deformations ${ }^{2}$ distributed through the plastic or glass according to the laws of classical elasticity. Many polymer glasses do show brittle fracture below the glass transition temperature $\left(T_{g}\right)$, and when this occurs no large plastic deformations are visible to the naked eye or even in the optical microscope. This led to the concept that large deformations did not occur in polymers below $T_{g}{ }^{12}$ As a consequence of this proposition it would, of course, follow that the impact strength of amorphous glasses was controlled by relaxation loss peaks relating to small deformations (generally $<1 \%$ ). In fact, however, the first proposition is untrue and the second has been found to have rather limited application to homogeneous plastics tested unnotched or with conventional blunt notches although a great effort has been devoted to searching out suitable correlations. ${ }^{13-16}$

A further point which has been demonstrated conclusively in recent years concerns the fundamental nature of the fracture process. Here it has been shown that when brittle fracture occurs with the conventional glassy polymers, the fracture process itself takes place by the formation and fracture of crazes which involve large local deformations ${ }^{17-20}$ as shown in Fig. 3(a) and (b). Only if the polymer molecular weight is reduced below that associated with the entanglement molecular weight ${ }^{19}$ is a smooth or relatively smooth fracture surface obtained (Figs. 4a and b)

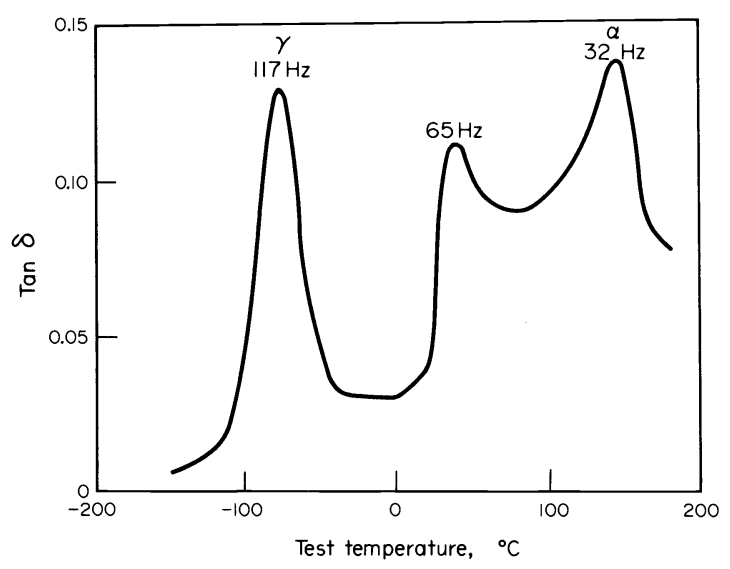

(a)

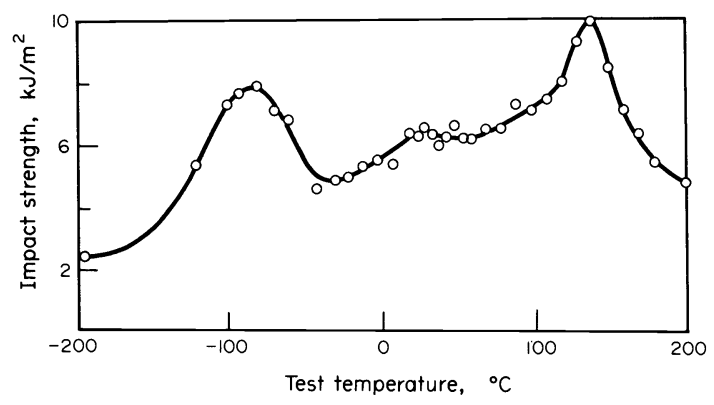

(b)

Fig. 2. Relaxation peaks and impact strength. (a) The effect of test temperature on $\tan \delta$ for a sample of polytetrafluoroethylene. The frequencies at the peaks were as marked. ${ }^{11}$ (b) The effect of test temperature on impact strength with very sharp notches for a sample of polytetrafluoroethylene as in (2a). 


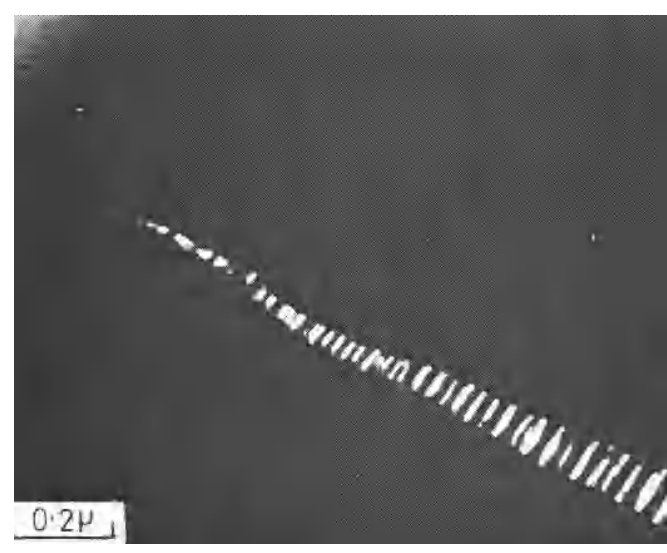

(a)

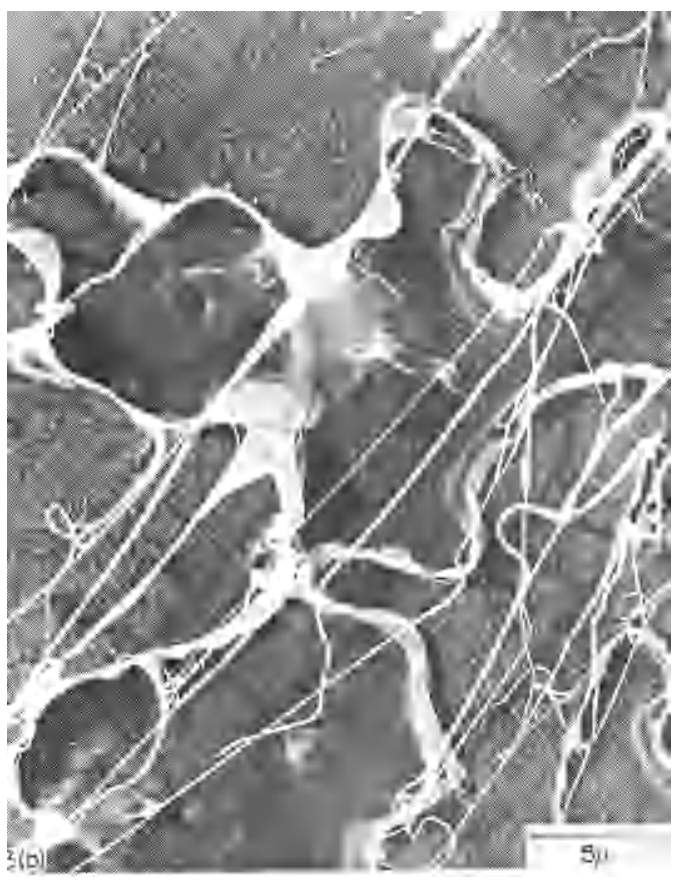

(b)

Fig. 3. (a) A craze in polystyrene (after Beahan et al. ${ }^{18}$ ). (b) Part of the fast fracture surface of polystyrene showing highly deformed material. ${ }^{19}$

and materials of this type are generally so weak as to be useless as plastic materials.

\section{The energy to fracture under impact}

When a plastic breaks it may undergo a reversible Hookean elastic strain of up to 0.05 before yield, whereas plastic strains, if they occur, will often be of the order of 1 or more. Under these conditions the elastic energy absorbed will be $(\sigma t / 40) \sim 25 \sigma_{f} \mathrm{~kJ} / \mathrm{m}^{3}$ and the plastic energy $\sim 1000 \sigma_{y} \mathrm{~kJ} / \mathrm{m}^{3}$ where $\sigma_{y}$ is the yield strength $\left(\mathrm{MNm}^{-2}\right.$ ). However since $\sigma_{y} \sim \sigma_{f}$ (normally within a factor of 2) and since the elastic energy is in any case taken up before yielding occurs, it is clear that a high energy absorption must be accompanied by substantial plastic deformation. Further, as already pointed out, even brittle plastics undergo large plastic strains at the point of fracture, which may even absorb enough energy locally to melt the polymer (Fig. 3b), so why are they brittle? The answer is that the volume of material absorbing this large amount of energy may be insignificant compared with the size of the test-piece. The total energy absorbed therefore still corresponds to the elastic terms only (slightly modified by relaxation losses). We conclude that in order to abtain a tough material the volume of polymer undergoing a large plastic strain must be as large as possible in relation to the test-piece.

Thus the problem of providing a plastic with a high impact strength is essentially a problem of plasticity and is concerned with avoiding the localisation of plastic strain. This is in part a problem of geometry as already discussed and in part a specific property of the plastic deformation process.

We may however note here that where plastics are reinforced by glass or carbon fibres, the filler will generally be capable of taking up a much greater elastic energy than the plastic e.g. $5-50 \times 10^{3} \mathrm{~kJ} / \mathrm{m}^{3}{ }^{21}$ when $25 \sigma_{f}$ might be $1-2.5 \times 10^{3} \mathrm{~kJ} / \mathrm{m}^{3}$. This is an important reason for the high impact strength of fibre reinforced plastics.

\section{Plastic instability}

It is a feature of plasticity processes, in metals as well as polymers, that deformation does not always extend uniformly through the test-piece. The reason for this is qualitatively simple. When plasticity begins it is often accompanied by strain softening, which in the case of tension may be intensified by geometric factors, so that the engineering stress falls substantially below that at which yielding is initiated. Plastic deformation then continues locally and may be confined to a small region near the point where it started. Examples of this effect in plastics include necking, shear bands and crazes. However the particular form of the response is affected by the constraints of the test-piece as well as by the polymer properties. ${ }^{22}$ Thus under plane strain conditions crazing and shear bands can be formed but bulk tensile yielding, which implies a decrease in thickness, is prohibited. Actual shear yield stresses may also be raised when the constraints on the system are increased in accordance with the modified von Mises (or other yield criterion) to which the material approximates.

The processes which initiate yielding in plastics, under different types of stress field have been extensively studied in recent years, so that yield criteria are becoming fairly well defined. ${ }^{22,33}$ However, the problem of plastic stability or instability is concerned with what happens next, a field in which much less quantitative information is available. ${ }^{24}$ However, the problem of shear bands has been treated by Bowden ${ }^{25}$ and Argon $^{26}$ and although different mathematical expressions were obtained, both agreed in concluding that the formation of narrow shear bands depends on a high value of the negative slope on the stress-strain curve $(\mathrm{d} \sigma / \mathrm{d} \epsilon)_{\epsilon}$. Bowden further demonstrated that when polystyrene was quenched by cooling from $100^{\circ} \mathrm{C}$ into ice water, this negative slope was greatly reduced ${ }^{25}$ and the shear bands changed over from discrete narrow bands to diffuse zones (Fig. 5).

Other work by Mills showed that the yielded zone at the base of a crack in PVC increased in width after annealing. ${ }^{27}$

Further, with regard to necking, the applicability of classical plasticity criteria has been demonstrated by Vincent ${ }^{28}$ and for crazing, Haward and Owen $^{29}$ have shown that the formation of a system of adjacent voids under tension accords with a simple plasticity model. 

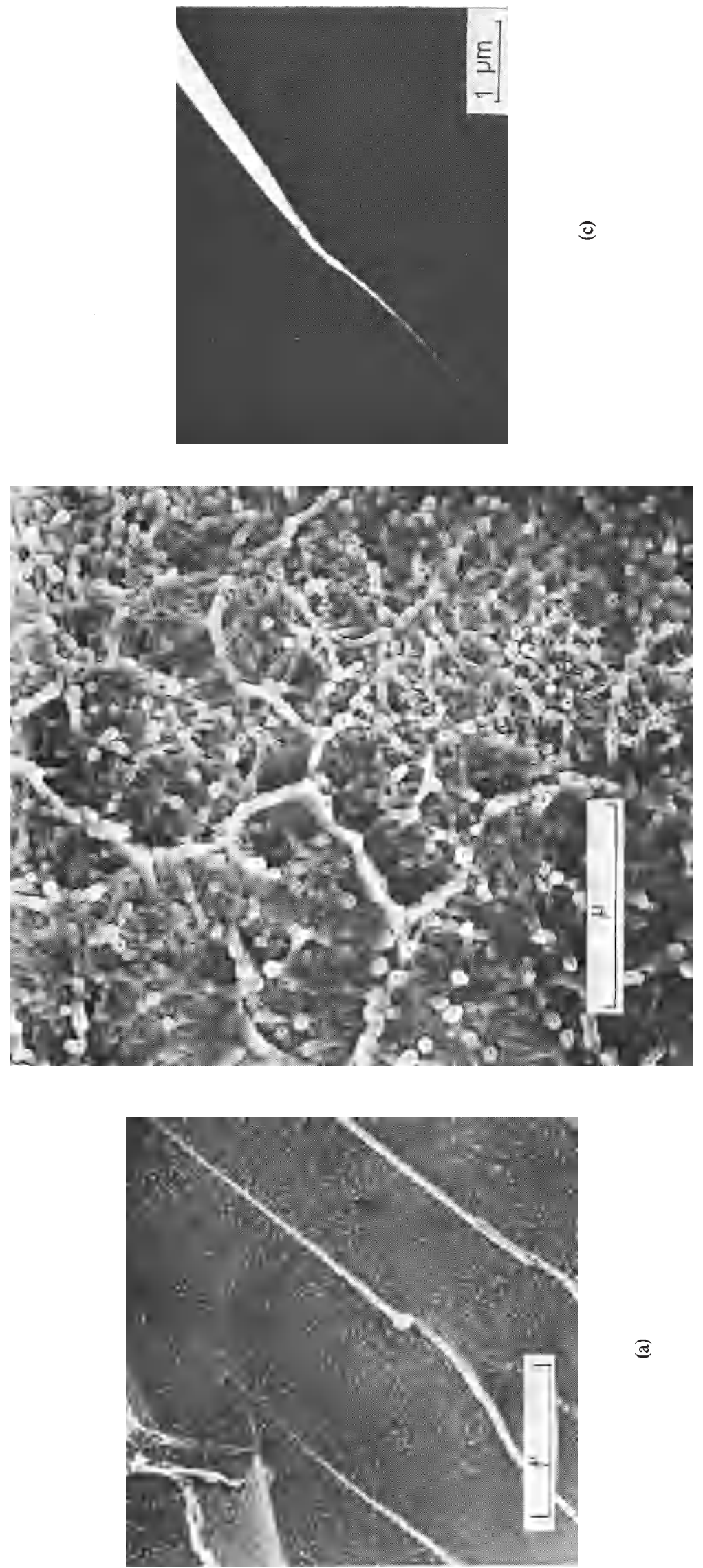

로을 물

政

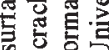

它安

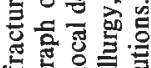

을

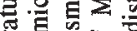

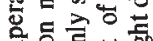

过

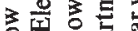

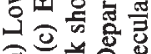

玉

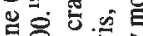

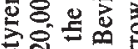

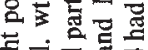

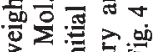

3 白

녈

递富

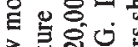

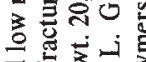

형

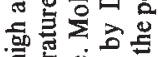

要

喽

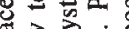

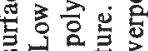

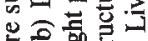

氖㗊

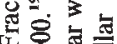

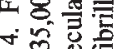

战安。 


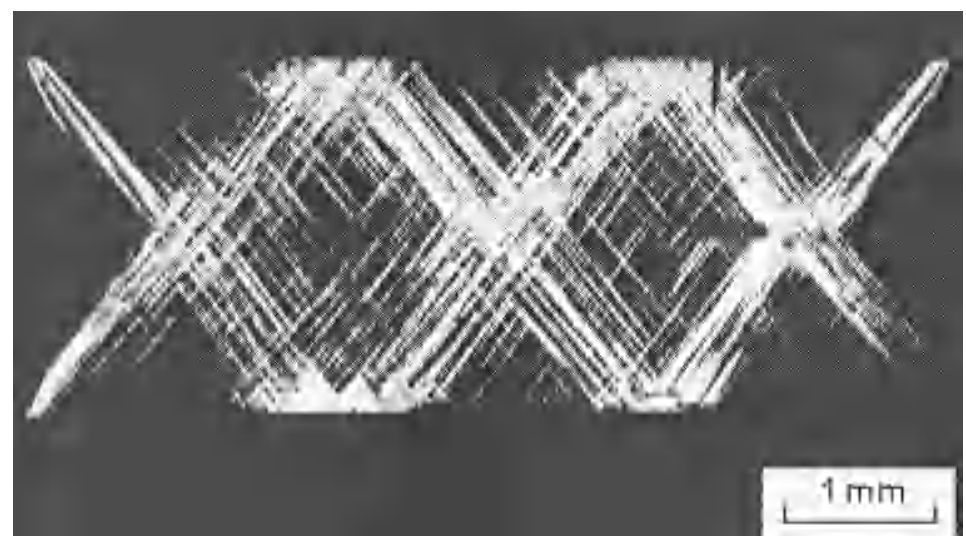

(a)

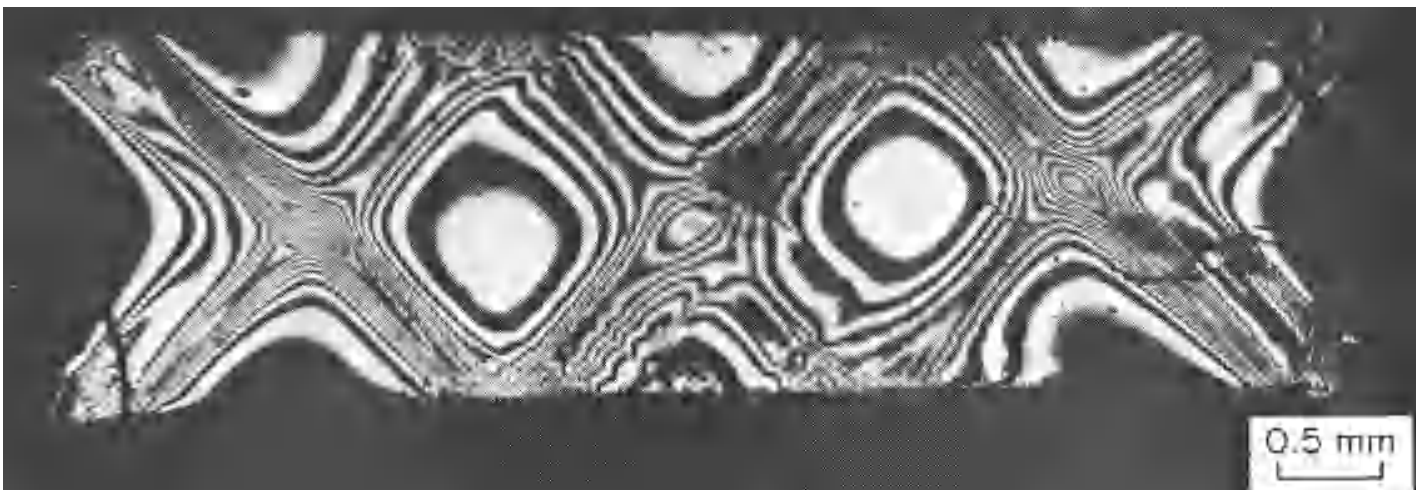

(b)

Fig. 5. Effect of quenching on shear bands in polystyrene ${ }^{25}$ (a) Cooled normally. (b) Quenched from $100^{\circ} \mathrm{C}$, showing more uniform deformations.

The effect of annealing on the impact strength of polycarbonate

Several workers have shown that when polycarbonate is annealed it gets more brittle..$^{15,30,31}$ Both Allen et al..$^{15}$ and Wyzgoski et al. ${ }^{31}$ have also demonstrated that annealing is not accompanied by a significant change in the position or height of relaxation loss peaks. It was therefore decided to investigate the relevance of the plasticity approach in this case. For this purpose, stress-strain curves were measured in tension and in plane strain compression ${ }^{32}$ and it was found that in all cases annealing led to an increase in the total fall in stress after yield and in the negative slope $(\mathrm{d} \sigma / \mathrm{d} \epsilon)_{i}$ as understood by Bowden ${ }^{25}$ and Argon (Figs. 6a and b). These changes were accompanied by a fall in impact strength, as previously found. Examination of two groups of test-pieces were then carried out to observe the affect of annealing on the amount of polymeric material subjected to plastic strain. One set consisted of normal broken ( $3 \mathrm{~mm}$ thick) test-pieces obtained from the blunt notched Charpy test as shown in Fig. 7. The second set were obtained in an incremental impact experiment of the staircase type, in which the test-pieces which had just failed to break were examined and it was similarly observed that the amount of plastic deformation was reduced after annealing. ${ }^{32}$ In each case the reduction due to annealing in the amount of material subject to plastic strain relates directly to the absorption of energy under impact. Thus with blunt notches, and test-pieces which are not too thick (plane stress field), substantial volumes of material are affected by large plastic strains leading to a high impact strength. This corresponds to the common experience that some homogenous glassy polymers, including polycarbonate and the plasticised cellulose esters, are tough. According to the above argument this type of toughness is a consequence of their limited strain softening and well developed orientation hardening properties. ${ }^{33,34}$ With more brittle materials, this condition can often be approached by pre-orientation of the polymer in the direction of the applied tension, which increases impact strength and reduces the tendency to craze. ${ }^{23}$

From the theoretical point of view, neither strain softening nor orientation hardening is well understood, but somewhat speculatively one might say that the former is associated with the breakdown of a localised structure at yield, ${ }^{32}$ and the latter with a strong entanglement network between polymer chains. ${ }^{35}$

\section{Crazing and rubber-toughening}

The occurrence of crazing leading on to crack propagation is normally associated with brittle fracture and low impact strength. This however depends on the size of the test-piece. If the sample tested were only a few microns long it would seem very tough. Alternatively, the number of crazes, and with it the volume of plastically deformed material, can be vastly increased by rubber-toughening. If 


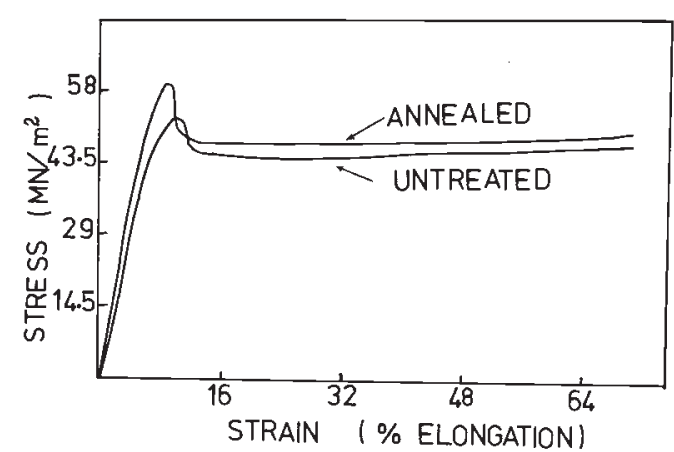

(a)

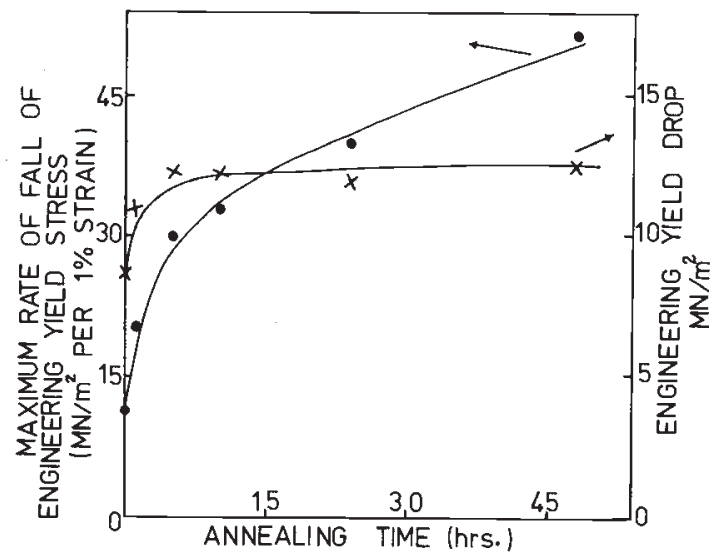

(b)

Fig. 6. The effect of annealing on stress-strain curves in polycarbonate. (a) Conventional curves in tension. (b) Effect of annealing time on maximum negative slope and on "yield drop".

shear bands are also formed, the toughening effect will be enhanced. The part played by crazes in this system was first demonstrated by Bucknall and Smith. ${ }^{36}$ who stretched a thin section of high-impact polystyrene (HIPS) on the stage of an optical microscope, and observed the formation of a large number of short crazes, at approximately $90^{\circ}$ to the applied stress. The crazes ran from one rubber particle to the next, and the size of each individual craze was therefore determined by the interparticle spacing. The area under observation finally broke at a local extension of about $50 \%$, which is similar to the extensions at break of macroscopic tensile specimens. In this way the total number of crazes formed is greatly increased so that the volume of plastically deformed material is raised by several orders of magnitude. This provides a high elongation at break and energy of fracture. The process, which has been confirmed in later work, ${ }^{37}$ is illustrated in Fig. 8. As it continues the rubber particles are deformed until one of the crazes becomes large enough to generate a catastrophic crack.

Rubber particles appear to have two separate but equally important functions in HIPS. Firstly, they act as stress concentrators, initiating crazing at applied stresses well below those at which crazes form in conventional polystyrene. Secondly, they act as craze terminators, preventing the growth of very large crazes. It is interesting to compare the effects of rubber particles and of glass beads upon the tensile behaviour of styreneacrylonitrile copolymer (SAN). Lavengood, Nicolais and Narkis have shown that SAN containing $43 \%$ by volume

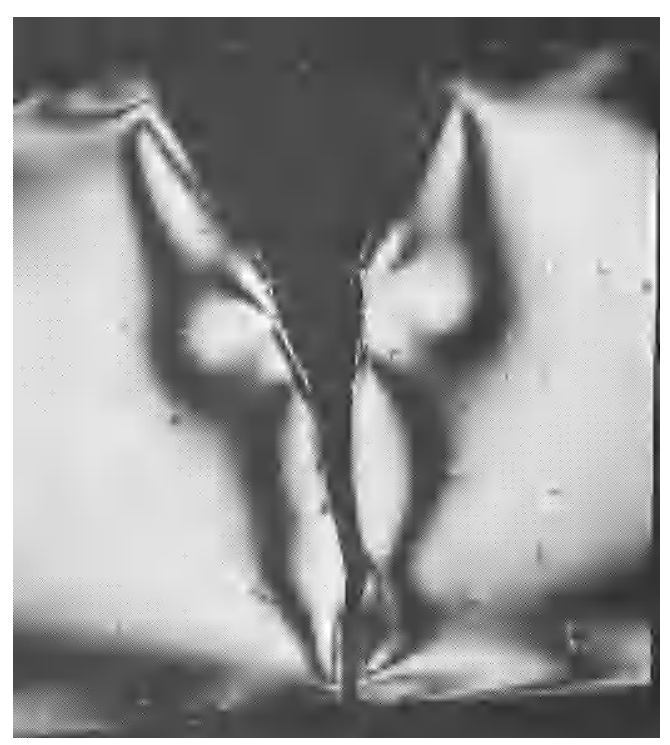

(a)

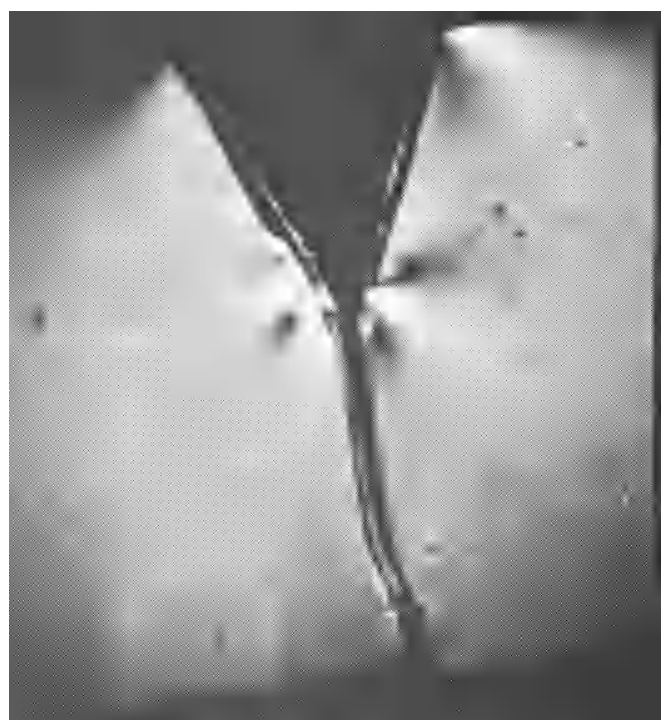

(b)

Fig. 7. Magnified photographs taken in polarised light of broken Charpy test pieces. (a) Untreated. Impact strength $12 \mathrm{~kJ} / \mathrm{m}^{2}$. (b) Annealed $130^{\circ} \mathrm{C} 16 \mathrm{hr}$. Impact strength $6 \mathrm{~kJ} / \mathrm{m}^{2}$. (Material supplied by Dr.R. P. Kambour.)

of spherical glass beads between 12 and $36 \mu \mathrm{m}$ in diameter yields in a similar manner to ABS (a rubber toughened form of SAN) ${ }^{38}$ Multiple crazing causes both materials to whiten at the yield point. The glass-filled material, however, breaks at an elongation of only $3 \%$, compared with $30 \%$ for an ABS having a higher yield point and lower volume loading of rubber particles (Fig. 9). In fracture mechanics terms, the rubber particles limit the sizes of the flaws (crazes) produced under applied stress, whereas the glass beads do not, with the result that some of the crazes quickly grow to macroscopic dimensions and cause fracture. Beyond the yield point the deformation of HIPS is due principally to multiple craze formation. Although the stress rises only slightly with strain in this region, the recoverable strain energy density 


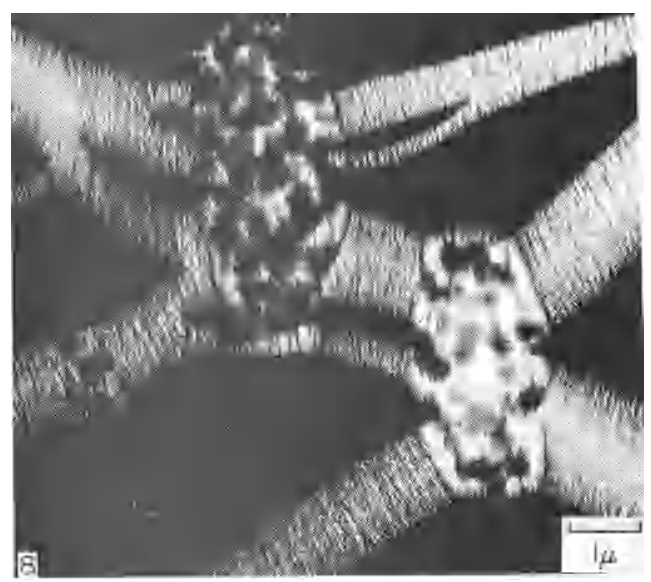

Fig. 8. Electron micrograph showing crazes between rubber particles in impact polystyrene. As the crazes are formed the rubber particles are distorted. Photograph by $\mathrm{A}$. Thomas and $\mathrm{M}$. Bevis, Dept. of Metallurgy, Univ. of Liverpool, (Private communication).

has been shown experimentally to increase linearly with strain. ${ }^{39}$ The reason is that a small but significant fraction of the energy absorbed is stored by the crazes in a reversible form. Fracture occurs when the stored energy density reaches a critical level which is determined by the properties of the material and the size of the flaws or cracks present.

In order to be effective as craze terminators, the rubber particles must be adequately bonded to the surrounding matrix. In styrene-based polymers, this is usually achieved by graft copolymerization between the components of the two phases. This may be achieved directly in the mass copolymerisation of styrene with butadiene rubbers, or by emulsion polymerisation, which may include a separate grafting step to provide adhesion between the rubber and the bulk polymer phase. (Fig. 10). Alternatively, a rubber having good adhesion to the matrix may be blended mechanically with the styrene polymer or copolymer. Block copolymers are particularly good in this respect. ${ }^{40}$ If adhesion is poor, as in latex blends of polybutadiene with styrene-acrylonitrile copolymer, the product is brittle. ${ }^{33,41}$ Instead of terminating an advancing craze, a poorly-bonded rubber particle simply becomes detached from the matrix, thus promoting further craze growth (Fig. 10a). The fracture surface of the ungrafted latex blend is similar to that given by the SAN glass bead composite previously mentioned ${ }^{38}$ (Fig. 10d).

Failure of the craze termination mechanism could also explain why small rubber particles, below about $0.5 \mu \mathrm{m}$ in diameter, are less effective than larger particles in toughening polystyrene.

\section{Role of shear bands}

The stress concentrations produced by rubber particles can also lead to the nucleation of shear bands. In some materials, crazes and shear bands nucleate simultaneously when a tensile stress is applied. Shear bands are formed approximately along planes of maximum resolved shear stress, and therefore intersect crazes at an angle of about $45^{\circ}$. Consequently, some interaction between the two types of plastic deformation is to be expected. Probably the most important interactions are those between existing shear bands and propagating crazes. Because of the high molecular orientation within shear bands, they act as effective barriers to craze propagation. ${ }^{42}$ Another possibility is craze termination through the generation of shear bands at the craze tip. There is direct evidence for mutual termination of crazes lying in different planes by this mechanism. ${ }^{43}$

Simultaneous formation of crazes and shear bands in a rubber-toughened polymer has been demonstrated by scanning electron microscopy. ${ }^{44}$ A blend of poly(2,6dimethyl-1,4-phenylene oxide) (PPO) with HIPS was deformed in tension, and etched to reveal the rubber particles and deformation bands. The micrographs provided evidence of termination of crazes through interaction with shear bands, and this evidence was supported by the kinetics of deformation discussed below. A typical micrograph is shown in Fig. 11.

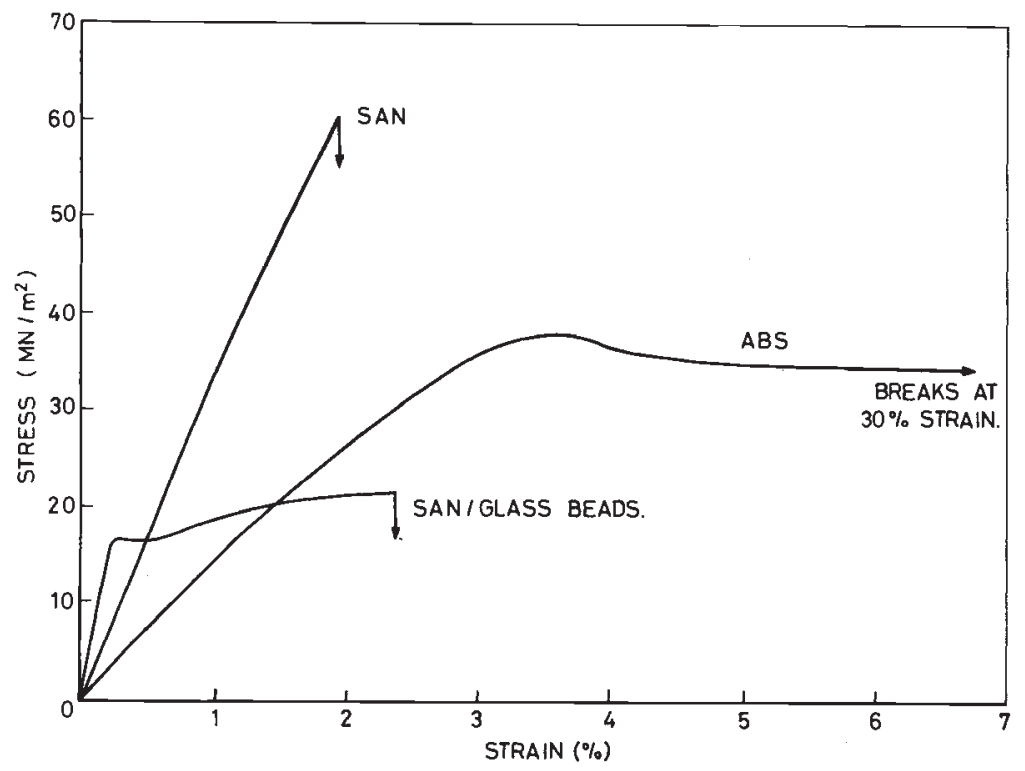

Fig. 9. Effects of glass beads and of rubber particles upon the tensile properties of styrene-acrylonitrile copolymer. After Lavengood, Nicolais and Narkis. ${ }^{38}$ 


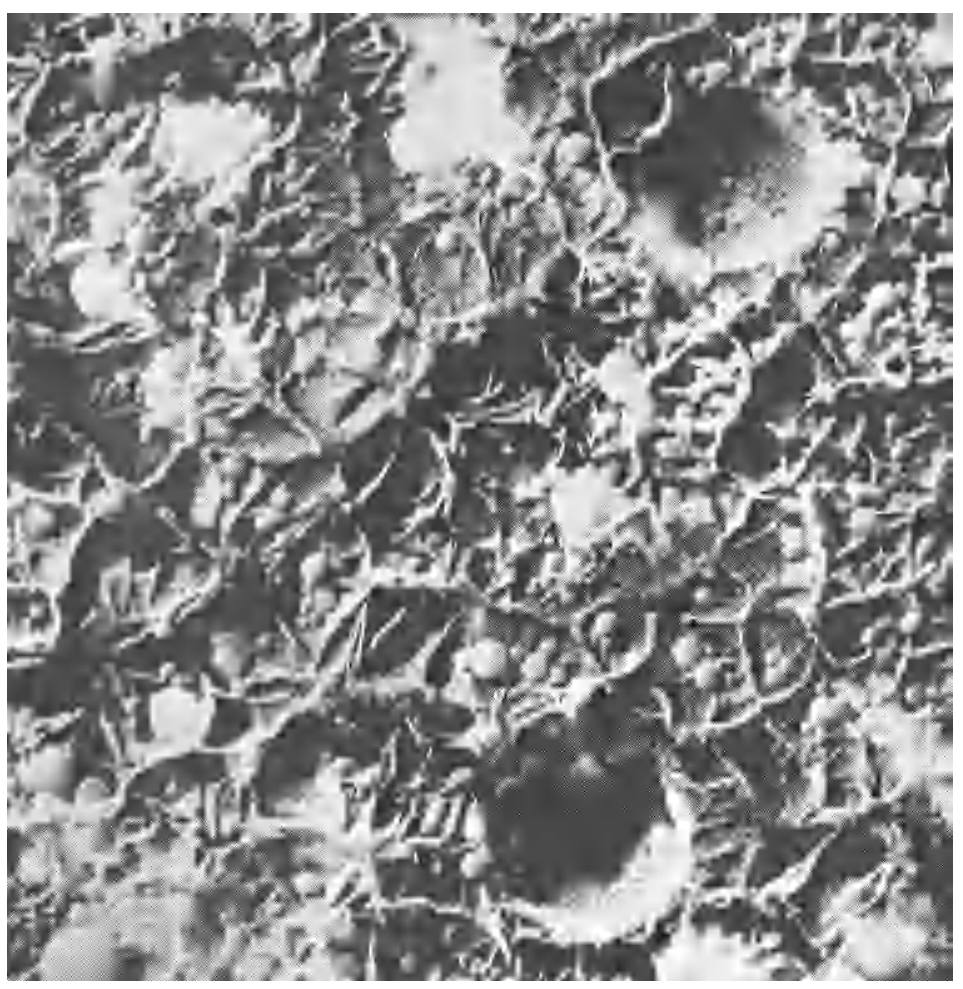

(a)

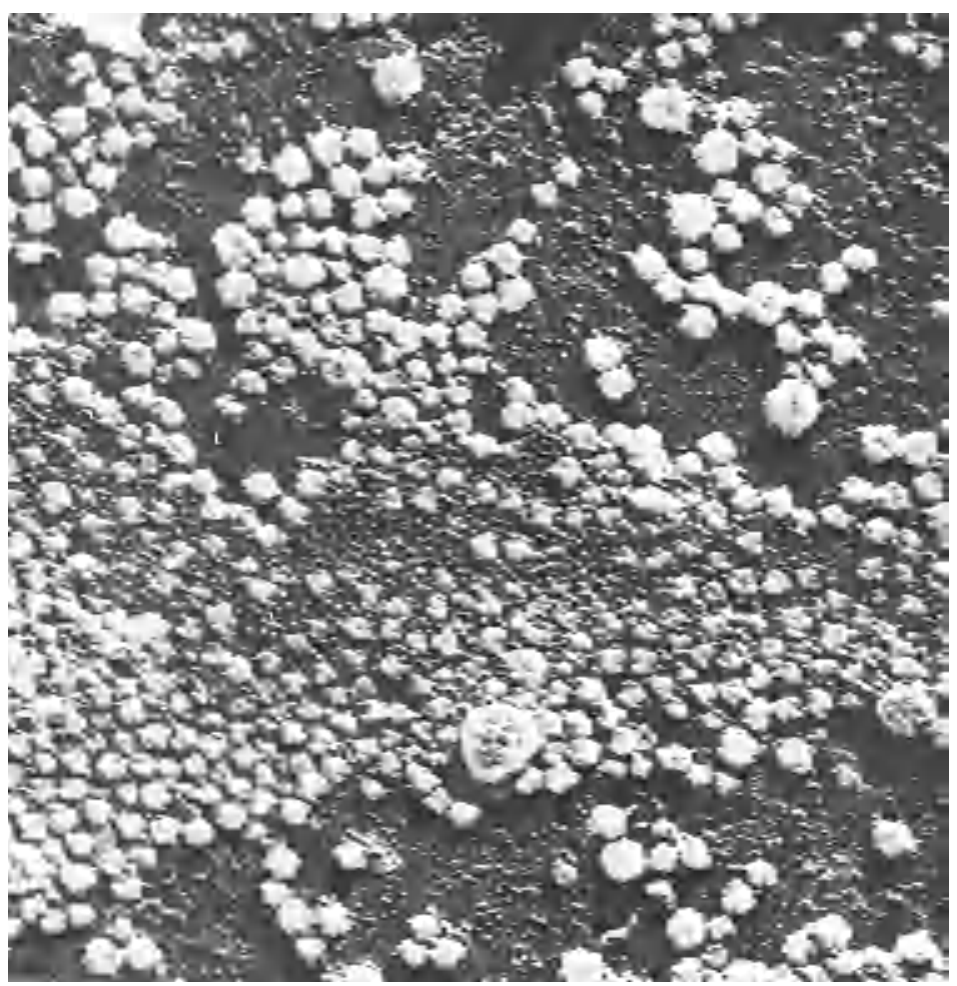




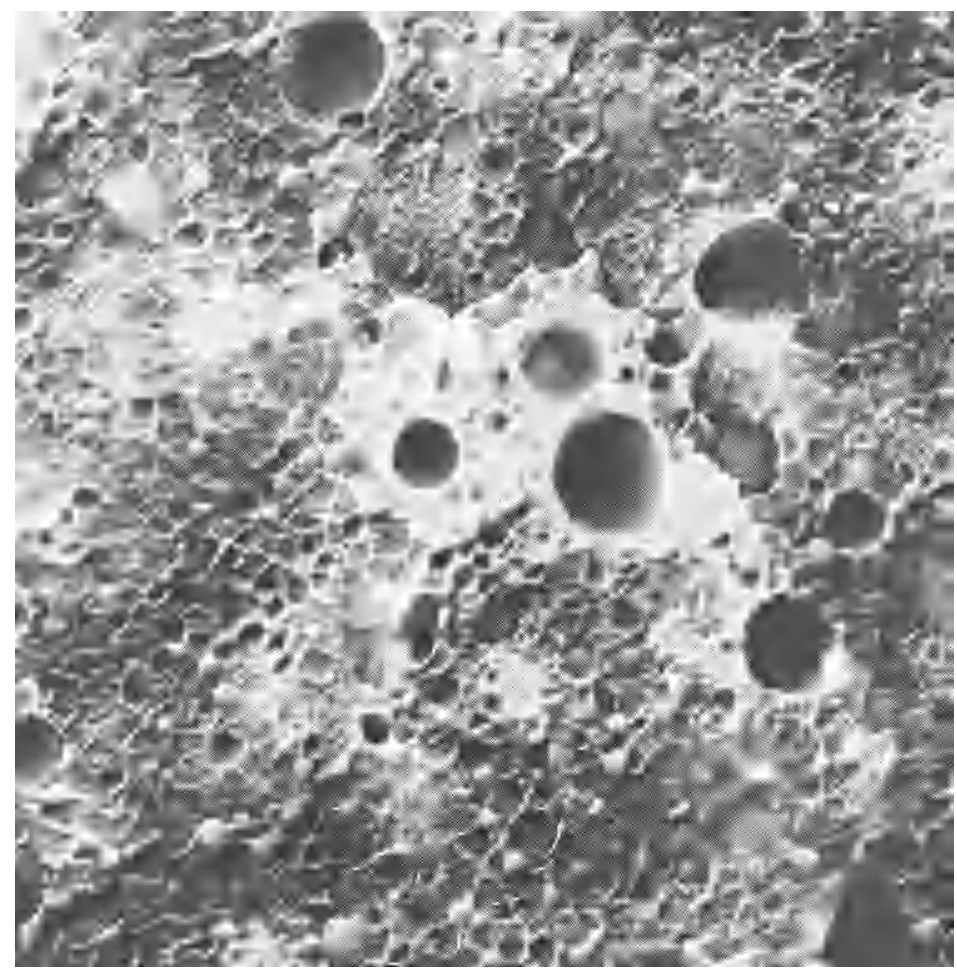

(c)

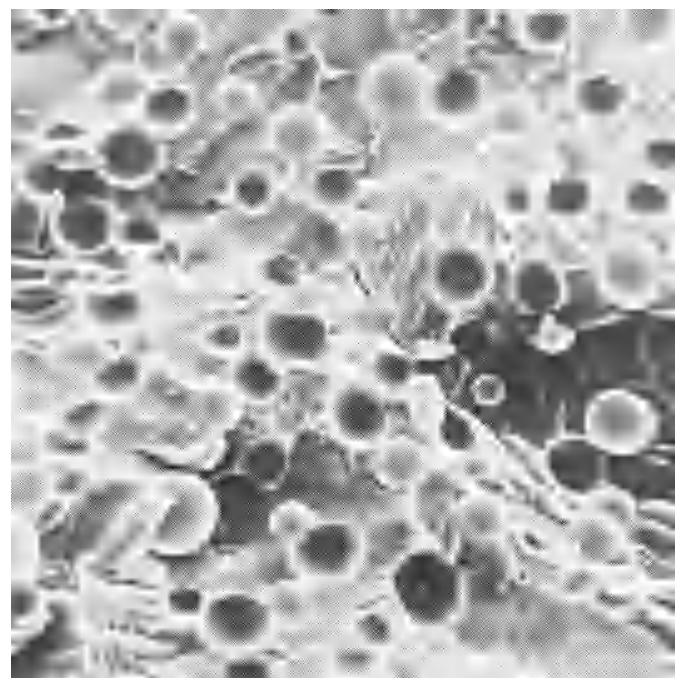

(d)

Fig. 10. The effect of grafting on the properties of an acrylonitrile-butadiene-styrene (ABS) polymer blend. (a) An electron micrograph of the fracture surface of a latex blend of a slightly cross-linked polybutadiene rubber with a $70 / 30$ styrene acrylonitrile copolymer latex. (b) Electron micrograph replica of a dried film. Particles of polybutadiene rubber which have been grafted with styrene/acrylonitrile copolymer. The smaller particles are free copolymer particles prepared at the same time. (c) A successful ABS (acrylonitrile butadiene styrene) latex blend. The grafted polybutadiene has been used with a styrene/acrylonitrile copolymer matrix to give a reinforced polymer of good impact strength. Note the evidence of adhesion between particles and matrix, and of the distortion of the matrix where particles have been pulled away during specimen preparation. ${ }^{41}$ (d) A fracture surface of SAN copolymer containing $21 \%$ (vol.) glass beads. The holes are relatively clean with little evidence of adhesion. ${ }^{38}$ The fracture surfaces in Figs. 10a and c, were prepared at liquid air temperatures. 


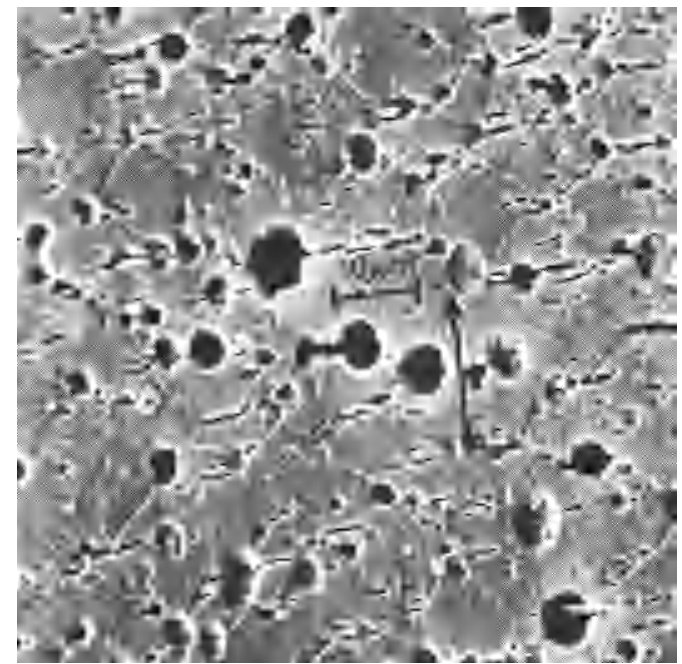

Fig. 11. Scanning electron micrograph of a polyphenylene oxideHIPS blend showing crazes perpendicular to the stress and angled shear bands. ${ }^{44}$ Arrow indicates tensile stress direction.

By acting in this way, shear bands lessen the need for large rubber particles which can control craze growth directly. Relatively small particles are able to initiate both crazes and shear bands. ${ }^{44}$ It is noteworthy that ductile polymers such as PVC and PPO are toughened by much smaller rubber particles than those required for more brittle materials such as polystyrene. SAN copolymer falls between these two extremes and is toughened by markedly smaller rubber particles than polystyrene.

\section{Deformation kinetics}

Bucknall and co-workers have developed a quantitative method for studying the mechanisms of rubbertoughening. Tensile deformations are considered as consisting of three components-elastic extension, crazing, and shear deformation. In order to distinguish these components, some simplifying assumptions are made. Elastic extension is assumed to be effectively timeindependent; crazing is assumed to cause no lateral contraction; and shear deformation is assumed to take place with negligible volume change. It follows that the extent of crazing in a tensile specimen can be determined simply by measuring the volume strain, and subtracting the elastic volume strain. Similarly, shear deformation is measured by subtracting the elastic contribution from the total lateral contraction.

The first measurements of this type were made on a high-accuracy creep rig. ${ }^{45}$ Longitudinal and lateral strains were measured simultaneously, in the range up to $5 \%$ and used to calculate volume strains. More recently, a similar approach has been applied to high-speed tensile testing, using a high-speed cine-camera to record large strains. ${ }^{46,47}$

Figure 12 compares results obtained by the creep method from HIPS and rubber-toughened PVC. The constrast is striking. Creep in HIPS is an accelerating process, beginning slowly, but becoming rapid after the initial period. The volume strain measurements clearly indicate that crazing is the dominant mechanism of deformation. There is little change in lateral strain $\Delta W / W$ with time, showing that shear deformation is relatively unimportant. In toughened PVC deformation is dominated by shear processes and there is only a small contribution from crazing. At these low deformations
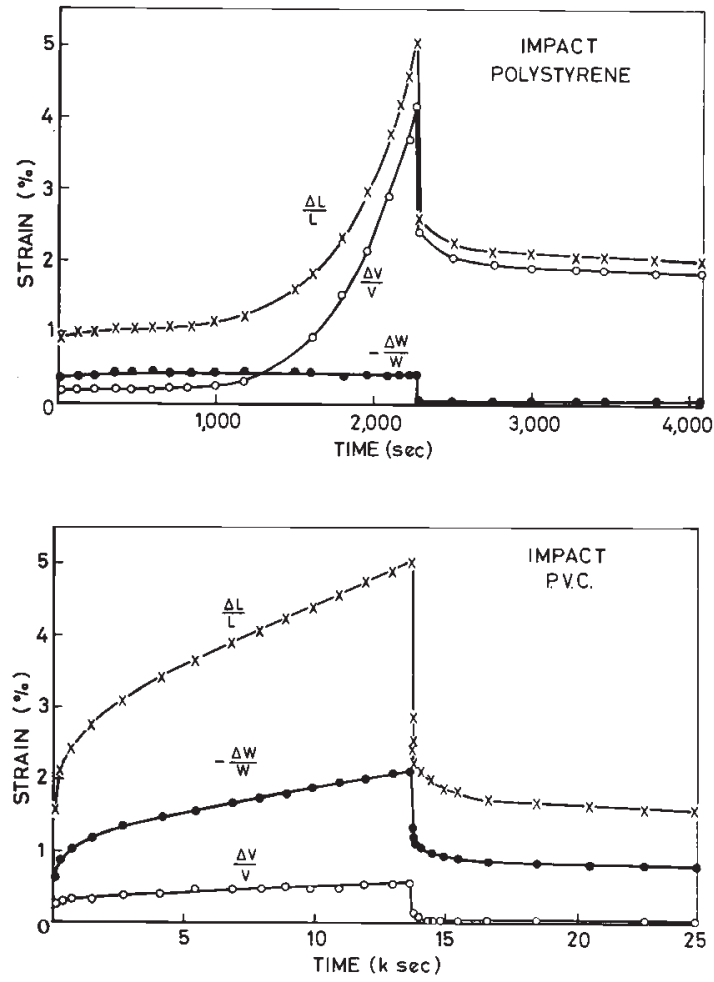

Fig. 12. Creep and recovery in rubber modified polymers. (a) High impact polystyrene (HIPS), $\sigma=19.7 \mathrm{MN} / \mathrm{m}^{2}$. (b) PVC $-5 \% \mathrm{ABS}$ blend, $\sigma=36.0 \mathrm{MN} / \mathrm{m}^{2}$.

shear bands are easily formed but the process tends to decelerate, in contrast to the crazing of HIPS shown above.

The contribution of each mechanism to deformation at any given stage of the test can conveniently be determined by plotting volume strain against the corresponding value of longitudinal strain, as illustrated in Fig. 13. In a material deforming entirely by shear, the volume is independent of strain, and the slope is therefore zero. Conversely, in a material deforming entirely by crazing, the slope is one. The ABS data presented in Fig. 13 show that the contribution of crazing to creep increases with both stress and strain. This pattern of behaviour is also observed in toughened epoxide resins, ${ }^{48}$ and probably occurs quite generally in rubber-toughened plastics, over a stress range which is characteristic of the material.

\section{Deformation mechanisms under impact loading}

These observations concerning ABS throw some light upon the problem of impact behaviour, not only in rubber-toughened plastics, but also in ductile notchsensitive materials such as rigid PVC. At high strain rates stresses and "yield drops" in tension tend to become larger ${ }^{35}$ and deformation becomes more localised. Also, because of differences in deformation kinetics between crazing and shear band formation, crazing becomes more dominant as the applied stress, and therefore the strain rate, increases. In unmodified $\mathrm{PVC}$, the result is a transition from ductile behaviour at low strain rates to brittle behaviour under impact loading. In rubbertoughened PVC, the same change in deformation mechanism produces a very tough failure under impact, in which the energy is absorbed principally by multiple crazing, but shear processes also contribute, both directly and by controlling craze propagation. Simultaneous crazing and 


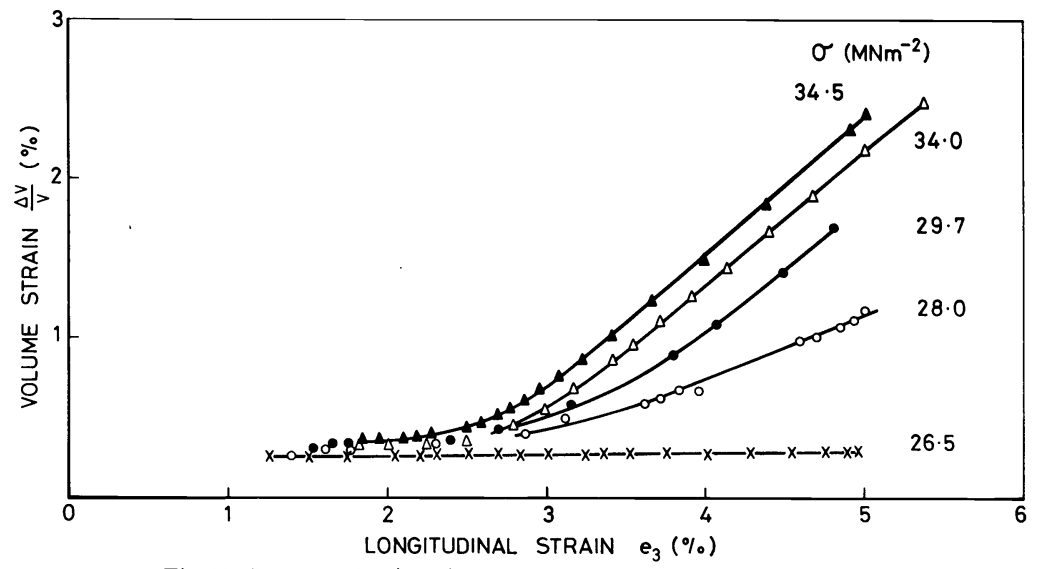

Fig. 13. Creep mechanisms in Cycolac T ABS over a range of stresses.

shear band formation have been observed in HIPS/PPO notched Izod specimens, using scanning electron microscopy. $^{49}$

In simple terms, both the crazing stress and the shear yielding stress are functions of the time at which observations are made. As the time under load is reduced, the shear yield stress increases more rapidly than the crazing stress. Rubber toughening turns this trend to advantage at high strain rates by exploiting the energyabsorbing potential of the craze mechanism.

The multiple-craze mechanism offers another advantage. An important factor in notched impact testing is the state of triaxial tension which is established at the base of the notch. In most materials, the resulting cavitation leads to brittle fracture. In rubber-toughened plastics, on the other hand, the tendency towards cavitation process, which is automatically multiplied by the rubber particle system.

\section{THE IMPACT STRENGTH OF SHARP-NOTCHED TEST PIECES}

As previously discussed, the impact fracture of sharp-notched specimens is initiation controlled in most polymers, so that all the necessary energy for fracture is stored in the specimen at the beginning of the crack growth. Polycarbonate, high density polyethylene and nylon 66 all of which are normally regarded as tough plastics, are relatively brittle in this sense. The value of $5 \mathrm{kJm}^{-2}$ for $G_{c}$ in polycarbonate is particularly low, ${ }^{8}$ indicating a very small amount of plastic deformation during the propagation of the crack.

The materials which gave the best performance in experiments with razor notches were the rubbertoughened plastics. Even in the presence of a very sharp notches, HIPS and ABS gave tough, propagationcontrolled impact fractures, ${ }^{8,9}$ with $G_{c}$ (or more strictly $\mathrm{J}_{c}$ ) values of 15 and $50 \mathrm{kJm}^{-2}$ respectively for the materials studied by Williams. ${ }^{8,9}$ The toughness is of course a function of rubber content in this class of polymers. It should be noted that this observation concerning propagation control applies to tests at room temperature. At low temperatures, especially below the $T_{g}$ of the rubber, impact fracture in rubber-toughened plastics is initiationcontrolled. ${ }^{33,50,51}$

\section{CONCLUSIONS}

The toughness of a polymer is a function of testing conditions and materials structure, both of which determine the extent of plastic deformation occurring before and during fracture. Important test variables include specimen geometry, strain rate, and temperature. Structural changes due to thermal treatment significantly affect impact strength in homogeneous polymers such as polycarbonate by altering the plastic yield characteristics. The addition of a disperse rubber phase increases the impact strength of a wide range of plastics by providing a multiple-craze mechanism for energy absorption, a plastic yield process which is enhanced by synergistic shear band formation in the more ductile polymers.

\section{REFERENCES}

'H. G. Tattersall and G. Tappin, J. Mat. Sci. 1, 296 (1966).

${ }^{2}$ A. A. Griffith, Phil. Trans. Roy. Soc. A221, 163 (1920).

${ }^{3}$ J. L. Glathart and F. W. Preston, Glass Technology, 9, 89 (1968).

${ }^{4}$ F. W. Preston, J. Am. Ceram. Soc. 14, 428 (1931).

${ }^{5}$ R. N. Haward, Phil. Mag. 7, 777 (1945).

${ }^{6}$ R. N. Haward, J. Soc. Glass Tech. 28, 133 (1944).

${ }^{7}$ G. P. Marshall, J. G. Williams and C. E. Turner, J. Mat. Sci. 8 , 949 (1973).

${ }^{8}$ H. R. Brown, J. Mat. Sci. 8, 941 (1973).

${ }^{9}$ E. Plati and J. G. Williams, Polym. Eng. Sci. 15, 470 (1975).

${ }^{10}$ J. P. Berry, Fracture Processes in Polymeric Solids. p. 157. Wiley, New York (1964); J. Polym. Sci. 59, 107, 313 (1961).

${ }^{11}$ P. I. Vincent, Polymer, 15, 111 (1974).

${ }^{12}$ F. Bueche, The Physical Properties of Polymers. p. 247. Interscience, New York (1962).

${ }^{13}$ R. F. Boyer, Polym. Eng. Sci. 8, 161 (1968).

${ }^{14}$ J. Heijboer, J. Polym. Sci. C16, 3755 (1968).

${ }^{15}$ G. Allen, D. C. W. Morley and J. Williams, J. Mat. Sci. 8, 1449 (1973).

${ }^{16}$ D. Stefan and H. L. Williams, J. Appl. Polym. Sci. 18, 1279 (1974).

${ }^{17}$ R. P. Kambour, Polymer 5, 143 (1964); J. Polym. Sci. A2, 4159 (1964).

${ }^{18}$ P. Beahan, M. Bevis and D. Hull, Phil. Mag. 24, 1267 (1971); J. Mat. Sci. 8, 162 (1972).

${ }^{19}$ R. N. Haward and I. Brough, Polymer 10, 724 (1969).

${ }^{20}$ S. Rabinowitz and P. Beardmore, Crit. Revs. Macromol. Sci. 1 , (1972).

${ }^{21}$ A. Kelly, Strong Solids. pp. 167-176. Clarendon Press, Oxford (1966).

${ }^{22} \mathrm{P}$. B. Bowden in The Physics of Glassy Polymers. (Edited by R. N. Haward) Chap. V. Appl. Sci. Publishers (1973).

${ }^{23}$ S. S. Sternstein, L. Ongchin and A. Silverman, Appl. Polym. Symp. 7, 175 (1968).

${ }^{24}$ R. N. Haward, The Physics of Glassy Polymers. Polymers. Chap. VI. Applied Sci. (1973).

${ }^{25}$ P. B. Bowden, Phil. Mag. 22, 455; (with S. Raha); 413 (1970).

${ }^{26}$ A. S. Argon, Inhomogeneity of Plastic Deformation.Am. Soc. for Metals, Metals Park, Ohio, p. 161 (1973).

${ }^{27}$ N. J. Mills, Eng. Fract. Mech. 6, 537 (1974).

${ }^{28} \mathrm{P}$. I. Vincent, Polymer 1, 7 (1960).

${ }^{29}$ R. N. Haward and R. J. Owen, J. Mat. Sci. 8, 1130 (1973). 
${ }^{30}$ J. H. Golden, B. L. Hammant and E. A. Hazell, J. Appl. Polym. Sci. 11, 1571 (1967).

${ }^{31}$ M. G. Wyzgoski and G. S. Y. Yeh, Intern. J. Polym. Mat. 3, 149 (1974).

${ }^{32}$ A. Cross, G. Adam and R. N. Haward, J. Mat. Sci. 10, 1582 (1975).

${ }^{33}$ R. N. Haward, Br. Polym. J. 2, 209 (1970).

${ }^{34} \mathrm{P}$. I. Vincent in Deformation and Fracture of High Polymers. (Edited by H. H. Kausch, J. A. Hassell and R. I. Jaffee) p. 287. Plenum Press, New York (1974).

${ }^{35}$ R. N. Haward and G. Thackray, Proc. Roy. Soc. A302, 453 (1968).

${ }^{36}$ C. B. Bucknall and R. R. Smith, Polymer 6, 437 (1965).

${ }^{37}$ R. P. Kambour and R. R. Russell, Polymer 12, 237 (1971).

${ }^{38}$ R. E. Lavengood, L. Nicolais and M. Narkis, J. Appl. Polym. Sci. 17, 1173 (1973).

${ }^{39}$ C. B. Bucknall, J. Mat. (ASTM) 4, 214 (1969).
${ }^{40}$ R. R. Durst, R. M. Griffith, A. J. Urbanic and W. J. van Essen, ACS Div. Org. Coat. Plast. Prepr. 34(2), 32 (1974).

${ }^{41}$ R. N. Haward and J. Mann. Proc. Roy. Soc. 282A, 120 (1964).

${ }^{42}$ R. P. Kambour, J. Poly. Sci. Macromol. Revs. 7, 1 (1973).

${ }^{43}$ S. B. Newman and I. Wolock, J. Res. Nat. Bur. Std. 58, 339 (1957).

${ }^{44}$ C. B. Bucknall, D. Clayton and W. E. Keast, J. Mat. Sci. 7, 1443 (1972).

${ }^{45}$ C. B. Bucknall and D. Clayton, J. Mat. Sci. 7, 202 (1972).

${ }^{46}$ L. C. Cessna, Polym. Eng. Sci. 14, 696 (1974).

${ }^{47}$ P. J. Fenelon and J. R. Wilson, ACS Div. Org. Coat. Plast. Prepr. 34(2), 326 (1974).

${ }^{48} \mathrm{C}$. B. Bucknall and T. Yoshii, to be published.

${ }^{49} \mathrm{C}$. B. Bucknall, unpublished observations.

${ }^{50}$ C. B. Bucknall and D. G. Street, J. Appl. Polym. Sci. 12, 1311 (1968).

${ }^{51}$ C. B. Bucknall, British Plastics 40(12), 84 (1967). 